\title{
GOVERNANÇA E AS NOVAS TECNOLOGIAS: PRINCIPAIS REFLEXOS DA INFORMATIZAÇÃO NA GESTÃO ADMINISTRATIVA DO PODER JUDICIÁRIO
}

\author{
GOVERNANCE AND NEW TECHNOLOGIES: KEY REFLECTIONS OF \\ INFORMATIZATION ON ADMINISTRATIVE MANAGEMENT OF JUDICIARY
}

${ }^{1}$ Roberto Correia Da Silva Gomes Caldas

${ }^{2}$ Antonio Donizete Ferreira Da Silva

\begin{abstract}
RESUMO
O artigo trata dos reflexos das novas tecnologias na organização administrativa do Poder Judiciário e apresenta boas práticas de gestão que combinam resultados econômicos e sociais aliados à sustentabilidade. Objetiva-se analisar como as novas tecnologias ajudam na governança do Judiciário, principalmente no que tange à transposição do suporte tradicional do processo em papel para o processo judicial eletrônico. Optou-se pela pesquisa bibliográfica e documental, utilizando-se o método dedutivo. Justifica-se a pesquisa pelo fato de a democracia e a globalização unirem diretamente a governança judiciária à informatização onde se busca conciliar uma administração de resultados com práticas sustentáveis.
\end{abstract}

Palavras chave: Governança judiciária; gestão; justiça; tecnologia, processo eletrônico.

\begin{abstract}
The article deals with the consequences of new technologies in the administrative organization of the Judiciary and has good management practices that combine economic and social outcomes allies sustainability. The objective is to analyze how new technologies help in the governance of the Judiciary, especially regarding the transposition of the traditional support process paper to electronic court case. We opted for the bibliographical and documentary research using the deductive method. Justified the search because of democracy and globalization connect judicial governance computerization where it seeks to reconcile an administration results with sustainable practices.
\end{abstract}

Keywords: Judicial governance; management; justice; technology; electronic process.

\footnotetext{
${ }^{1}$ Mestre e Doutor em Direito do Estado, respectivamente, em Direito Tributário e Administrativo pela Pontifícia Universidade Católica - PUC, São Paulo, (Brasil). Professor dos Cursos de Mestrado e Bacharelado em Direito na Universidade Nove de Julho - UNINOVE, São Paulo, (Brasil). E-mail: robertocsgcaldas@ uol.com.br

${ }^{2}$ Mestrando em Direito pela Universidade Nove de Julho - UNINOVE, São Paulo, (Brasil). Pós-Graduado em Direito e Processo do Trabalho pela EPD. Graduado em Direito pela UNIP. Servidor Público Federal no TRT da $2^{\text {a }}$ Região. E-mail: emaildodonizete@yahoo.com.br
} 


\section{INTRODUÇÃO}

A Constituição Federal de 1988 traz como um de seus princípios fundamentais a independência e a harmonia entre os Poderes conforme prevê o art. $2^{\circ}$, da Carta Política. Para reforçar esta ideia, o texto Constitucional, a partir da Emenda Constitucional no 45, de 30 de dezembro de 2004, que dispôs sobre a 'Reforma do Judiciário', conferiu a esta função de Poder o chamado "autogoverno" (em alusão ao princípio da autotutela) no campo administrativo com a criação do Conselho Nacional de Justiça (CNJ).

Partindo dessas premissas, no que tange à organização judiciária, o Brasil tem um sistema relativamente complexo. Somente pelos números da Justiça pátria, em função da significativa dimensão territorial do país, tem-se a certeza de que uma cultura de governança judiciária se faz necessária para a "máquina" fluir, o que significa dizer, uma regulação para que haja gestão, controle e fiscalização com eficácia, eficiência e efetividade operacional.

Porém, as políticas estruturais e de gestão impõem variada gama de intervenções, fazendo com que a cultura de governança se faça necessária, ainda mais quando levado em conta o atual e irreversível avanço tecnológico, onde a democracia e a globalização são dois fatores que fomentam e movem a imperiosa informatização no Poder Judiciário.

A democracia, em sentido amplo e contemporâneo, cobra eficiência, eficácia, efetividade e sustentabilidade, segundo um modelo que pressupõe controle social e participação popular nas decisões, mediante, principalmente, os valores e princípios obtidos da governança corporativa.

Por sua vez, a globalização gera a necessidade de troca de informações, rapidez, adequação e sustentabilidade das práticas de gestão ao novo ambiente social que, hoje, não é mais local, e, sim, global, com uma sociedade contemporânea conectada, direta ou indiretamente, cada vez mais à tecnologia da informação, novel realidade esta a impor, a seu turno, adaptações não apenas aos 'desplugados'3 , mas também ao Judiciário, o qual deve criar ferramentas para propiciar um efetivo controle social de suas políticas com participação dos interessados.

Assim, diante da evolução tecnológica e de seus impactos na gestão administrativa do Poder Judiciário, pergunta-se: quais os principais reflexos da informatização no que tange à gestão administrativa do Poder Judiciário? A virtualização do processo judicial gera

\footnotetext{
${ }^{3}$ Neologismo para se referir aos que sejam reticentes, avessos, ou não estejam conectados a redes sociais ou mesmo se utilizando de tecnologias de vanguarda para desempenho de suas atividades cotidianas.
} 
eficiência e efetividade com sustentabilidade? Quais as boas práticas de gestão advindas da informatização?

Diante dessa problemática, objetiva-se analisar as principais mudanças trazidas para a organização administrativa do Poder Judiciário diante da implementação do processo judicial eletrônico, bem como apresentar boas práticas de gestão com o uso de ferramentas tecnológicas que ajudam na governança e aliam eficiência com sustentabilidade.

Para isso, no primeiro tópico serão analisadas as principais inovações trazidas pela virtualização e a transposição do suporte do processo em papel para o eletrônico, na perspectiva das alterações administrativas oriundas do processo judicial eletrônico.

No tópico seguinte, se abordará a governança administrativa e se apontarão as mudanças físicas e de rotinas procedimentais da informatização. Também serão analisados conceitos da ciência da Administração nos seus aspectos relevantes para o Direito.

Ao final, serão apontados alguns dos desafios e perspectivas da gestão administrativa, apresentando-se as boas práticas de gestão com o uso da tecnologia, como, por exemplo, a criação de ferramentas eletrônicas de protocolos administrativos que objetivam a redução de custos com sustentabilidade e a criação do chamado home office, entre outras boas práticas de gestão que buscam gerar eficiência com inclusão social e sustentabilidade.

Justifica-se a presente pesquisa em razão da relevância que a eficiência administrativa traz para a prestação jurisdicional, principalmente com o auxílio das novas tecnologias e da necessidade de se afirmar uma cultura de governança no Poder Judiciário para se aplicar, de fato, o chamado tripé da sustentabilidade.

A metodologia de trabalho deverá centrar-se nos aspectos principais estabelecidos para uma pesquisa interdisciplinar que envolve temas de Direito Administrativo e da Administração, com seu tratamento específico voltado à administração pública da Justiça, devido primordialmente ao caráter singular que deve estar presente em toda análise de um sistema jurídico cujo foco se baseia em conferir maior segurança jurídica no âmbito das relações entre o Estado e o particular quando da prestação dos serviços para uma eficaz, eficiente e efetiva dicção do Direito (jurisdição).

A técnica de pesquisa utilizada é a da revisão bibliográfica, utilizando-se de estudos especializados principalmente em Administração Pública e eficiência administrativa, bem como em literatura especializada na virtualização do processo judicial.

Para o desenvolvimento do estudo e suas correlatas conclusões, utilizou-se o método dedutivo, de sorte a permitir analisarem-se os benefícios trazidos para a atividade de prestação 
jurisdicional pela eficiência administrativa alcançada com a introdução do processo digital, e suas inovações tecnológicas, aliada às boas práticas de governança regulatória.

\section{PROCESSO JUDICIAL ELETRÔNICO: EFICIÊNCIA E SUSTENTABILIDADE}

No atual estágio de globalização ${ }^{4}$ é quase impensável não se falar em tecnologia, seja na perspectiva pessoal - onde a conexão com o mundo se dá em segundos pelo uso da internet -, seja na perspectiva estatal - com a efetivação de um Governo Eletrônico ${ }^{5}$ que incentiva o controle social e a participação popular por meio da inclusão digital e da cidadania em sentido amplo -, de forma a permitir por parte da sociedade o acesso facilitado às informações governamentais e aos meios de intervenção nas políticas públicas locais e regionais.

Ante essa perspectiva, o Judiciário brasileiro - ainda que relativamente atrasado -, tem buscado cada vez mais se valer das tecnologias e de técnicas de comunicação para dar maior eficiência à prestação jurisdicional. Nesse sentido, Santos (2005, p. 87), ao versar sobre os avanços tecnológicos e o contexto em que se aplica ao Poder Judiciário, aduz que

A questão das relações entre as novas tecnologias de comunicação e de informação e o sistema judicial é uma subquestão de um debate muito mais amplo sobre o significado económico, social, político e cultural da revolução em curso nas tecnologias de informação e de comunicação. Falar de revolução implica já assumir a grande magnitude das transformações que ocorrem sob os nossos olhos. Essa magnitude aparece formulada de modo diferente nos diferentes campos sociais.

Consoante apontam Adorno e Soares (2013, p. 66) ao asseverarem sobre os meios para se obter agilidade na tramitação processual

A Reforma do Judiciário destacou a celeridade processual como princípio a ser almejado pelos órgãos desse poder. Importante instrumento para se alcançar esse objetivo traçado pelo legislador é o uso de recursos de informática para a prática dos atos processuais.

Será esse o motivo para a informatização dos processos judiciais? Não se pode responder prontamente, mas a eficiência administrativa judiciária, em grande medida, será fruto dessa inovação. Para Jorge Neto, Cavalcante e Meneses (2013, p. 50) “A adoção da tecnologia informática na solução de conflitos pelo judiciário, como visto, é um instrumento poderoso na eliminação de ineficiências. Por consequência, favorece o efetivo acesso a ordem jurídica justa e ágil”".

\footnotetext{
${ }^{4}$ Adota-se aqui a perspectiva de Beck (1999, p. 71), segundo a qual aponta que globalização se dá no quadro onde "Agora se inicia uma era pós-política internacional, na qual os atores nacionais-estatais são obrigados a partilhar o cenário e o poder global com organizações internacionais, companhias transnacionais, além de movimentos políticos e sociais transnacionais".

${ }^{5}$ Portal adaptado para o conteúdo da Estratégia da Governança Digital, contribuindo para a promoção do acesso às informações, a melhoria dos serviços públicos digitais e a ampliação da participação social: BRASIL. Governo Eletrônico. Disponível em: http://www.governoeletronico.gov.br/. Acesso em 19 de jun. 2016.
} 
Ainda em relação ao tema da eficiência, deve-se mencionar que há doutrinadores que entendem ser relevante realizar sua distinção de eficácia e efetividade, de modo que se possa compreender o escopo e fundamento das normas adotadas para alcançá-la e concretizá-la sob a perspectiva administrativa. Neste sentido, segundo Prazeres, deve-se entender por eficácia e eficiência, respectivamente

(...) medida do hiato que pode existir entre os resultados obtidos e as metas ou objetivos da qualidade especificados. Relaciona-se com o fazer as coisas certas, com o que deve ser feito, com o resultado do que se fez. É, em última análise, o grau com que as expectativas dos clientes são atendidas (1997, p. 79).

(...) relação entre os recursos humanos, as máquinas e o capital investido e os resultados advindos do uso desses recursos utilizados para produzir bens e serviços. Em termos financeiros, a eficiência é quantificada pela relação entre a receita e os custos mais despesas. Relaciona-se com o fazer certo, com a forma como as coisas são feitas (1997, p. 79-80).

Conforme Fernandes (2003, p. 89), “(...) enquanto a eficácia é atingir o objetivo, eficiência é atingir o objetivo da melhor maneira possível”. Em termos jurídicos, a eficiência, enquanto integrante do quadro de deveres indeclináveis do administrador público, é “(...) entendida como a melhor realização possível de gestão dos interesses públicos em termos de plena satisfação dos administrados com os menores custos para a sociedade e identificada com a realização otimizada das políticas públicas de derivação constitucional” (Moreira Neto, 2008, p. 37).

Já quando se trata da questão da efetividade, conforme Ferraz Júnior (2006, p. 113)

sentido jurídico da efetividade se refere mais ao plano pragmático, podendo dar-se uma norma eficaz que não seja de fato obedecida e aplicada. Pragmaticamente, não haveria a necessidade de saber o que ocasiona as condutas conforme ou contrárias às normas; (...) a efetividade é relação de adequação entre o relato e o cometimento de uma norma, num sentido inclusivo, abarcando o nível sintático e o semântico.

No momento, dentro de um quadro de constantes e significativos avanços tecnológicos, o Poder Público, visto como um todo, deve adaptar-se à hodierna sociedade cada vez mais, por isso, "digital". Santos (2005, p. 83) indica que "A profissionalização da informação e seus fluxos, combinada com a separação total entre informação relevante e informação irrelevante, foram os dois pilares em que assentou a legitimidade política dos tribunais modernos".

E para se dar maior efetividade a uma política judiciária que tenha uma administração mais ágil da Justiça, vê-se como necessário não só a substituição do ambiente físico tradicional dos processos, mas também de todos os serviços relacionados ao Poder Judiciário, vocacionando-se, assim, para uma gestão de resultados com o uso das novas 
tecnologias, cuja implantação pressupõe mecanismos de interação das pessoas com esse novo ambiente virtual de características próprias.

Com efeito, o processo judicial não pode modernizar-se isoladamente. É necessário que a legislação se altere e os operadores do Direito, com os serventuários da Justiça inseridos na própria organização do Poder Judiciário, realizem suas funções e atividades conforme os paradigmas do atual mundo globalizado e dinâmico em que vivemos. Como aponta Moreira Neto (2009, p.223)

Este resultado, portanto, ele próprio - e não apenas os processos empregados para alcançá-lo - pode e deve ser submetido aos critérios que presidiram aos trâmites juspolíticos levados a efeito deste seu planejamento até a sua execução, ou seja, também devem estar conformados aos princípios de legitimidade e de eficiência.

Deve o Judiciário criar meios de gerar resultados com accountability ${ }^{6}$, disclosure, compliance e fairness, sendo que, neste aspecto, o controle eletrônico agrega ainda a sustentabilidade. Santos (2005, p. 93) afirma que

Os sistemas informatizados de gestão de processos são uma ferramenta essencial para a organização e tratamento, de forma rápida e eficiente, de grandes quantidades de informação e de documentos, tornando mais rápido e eficiente o trabalho dos tribunais. Por exemplo, eliminam a necessidade de realização de certas tarefas repetitivas; possibilitam a publicidade de informação relevante, sem que tal implique a realização manual dessa tarefa pelo funcionário judicial ou deslocações inconvenientes e morosas ao tribunal; permitem a recepção de documentos; ou a consulta de processos por via electrónica.

É de se ressaltar, ainda, que o processo eletrônico é uma ferramenta que permite ampla interação com os elementos do chamado tripé da sustentabilidade, o Triple Bottom Line - na expressão cunhada por John Elkington $(2004)^{7}$-, correspondendo, direta ou indiretamente, aos resultados de uma organização medidos, a grosso modo, em termos de ganhos sociais, ambientais e econômicos.

Sob o aspecto social, o processo judicial eletrônico é inclusivo em termos de acesso à justiça, quer por seu viés formal - ao viabilizar contornarem-se quaisquer dificuldades pessoais ou estruturais -, quer por seu viés material - ao tornar o processo, em si, mais célere e com sua duração, dessa forma, mais razoável -, possibilitando uma satisfatória prestação jurisdicional, com efetiva solução dos conflitos. Quanto ao aspecto ambiental, pode-se afirmar que o

\footnotetext{
${ }^{6}$ Não existe um termo único em português que defina a palavra accountability, havendo que se trabalhar com uma forma composta. Buscando uma síntese, accountability encerra a responsabilidade, a obrigação e a responsabilização de quem ocupa um cargo em prestar contas segundo os parâmetros da lei, estando envolvida a possibilidade de ônus, o que seria a pena para o não cumprimento dessa diretiva. A respeito, vide Pinho e Sacramento (2009)

${ }^{7}$ A expressão criada por John Elkington também é conhecida como os "três P's" (people, planet and profit) ou, em português, "PPL" (pessoas, planeta e lucro). Segundo o autor, esse conceito surge da necessidade de que para ser sustentável, uma organização deve ser financeiramente viável, socialmente justa e ambientalmente responsável (2004).
} 
processo eletrônico é sustentável pela drástica redução do consumo e utilização dos recursos naturais e energéticos. Com isso, o terceiro aspecto de cunho financeiro tem seus ganhos de melhoria bastante evidenciados desde a economia de escala feita pelos Tribunais.

Importante notar-se, todavia, que o processo judicial eletrônico, por si só, não gera eficiência com sustentabilidade sem que o fenômeno da informatização não seja difundido e culturalmente aceito pela comunidade jurídica, cuja colaboração é vital para torná-lo também efetivo. Nesse sentido, Mata Diz e Caldas, sob o enfoque financeiro, aduzem (2015, p. 58)

Cabe ressaltar que o aspecto econômico, dentro da concepção atual do orçamento público, ganha grande relevo, principalmente em virtude da evolução da função do Estado no desempenho da atividade financeira segundo uma ideia de parceria, de colaboração, de consenso, de concertação com o setor privado nos gastos públicos, de sorte que se deem de maneira mais eficiente, isto é, otimizada e harmonizada com as necessidades públicas de cada setor da sociedade.

E, devidamente difundida e assimilada pela comunidade jurídica, a informatização aliada à cultura de governança permite um efetivo controle pelas metas, além de fiscalização e transparência, pois, como bem aduz Atheniense (2013, p. 11), “Os pilares básicos da governança são: participação, Estado de Direito, transparência, responsabilidade, orientação por consenso, igualdade e inclusividade, efetividade e eficiência, prestação de contas (accountability)". E continua o autor

Nenhum programa de computador se aperfeiçoa sem que haja estratégia disciplinada de desenvolvimento que propicie a efetiva coleta constante de sugestões de seus principais usuários. Programa de computador deve ser encarado como um produto inacabado, que deriva da inteligência humana, que é inesgotável. Como se sabe, o cliente sempre tem razão; é necessário ouvi-lo para aprimorar um produto ou serviço. Essa lição ainda não foi totalmente colocada em prática pelos tribunais (Atheniense, 2013, p.13).

Sintetizando a ideia, Bertoncini e Corrêa (2013, p. 129) reconhecem que

O processo eletrônico é uma realidade que não mais pode ser negada. Mesmo que se reconheça a necessidade de reflexão acadêmica sobre o tema, de alterações legislativas, de formação de uma nova cultura de justiça, menos burocrática e mais próxima da população, é fato inegável que o processo virtual já vem demonstrando ser um importante meio de concretização da cidadania, afinal, a seu modo, vem proporcionando o incremento da celeridade processual e do princípio da razoável duração do processo.

$\mathrm{Na}$ prática forense, tais ideias já foram albergadas pela Lei do Processo Judicial Eletrônico (Lei n. 11.419/06), a qual trouxe várias mudanças no que tange à organização administrativa do chamado processo colaborativo.

Em suma, diante do contínuo avanço dos meios de comunicação eletrônica, é inevitável uma integração dos cenários político, jurídico, econômico, ambiental e social, nos quais a tecnologia ganha espaço e utilidades nunca antes pensadas. 


\section{A GOVERNANÇA JUDICIÁRIA: GESTÃO E INFORMATIZAÇÃO}

Bresser Pereira (1998, p.33) aduz que "governança é a capacidade financeira e administrativa, em sentido amplo, de um governo implementar políticas". A governança pública envolve a maneira como o ente público organiza e presta os serviços públicos; a forma de gestão dos recursos públicos; os meios de expressão para a gestão de competências do seu quadro de pessoal; o modo como divulga suas informações e se relaciona com a sociedade civil. Chaves, por sua vez, (2014, p. 31), adota uma visão sistêmica de governança

Logo, quando se fala em governança, cuida-se não somente de um olhar interno, de mera gestão da máquina judiciária, mas da própria projeção da garantia institucional de autogoverno do Poder Judiciário, que implica estabelecer também olhares e relações externas aos domínios dos tribunais, até porque muitos avanços internos dependem de articulação institucional com os outros Poderes, tendo em vista os traços de harmonia e interação fixados na organização política prevista na Constituição Federal.

O Poder Judiciário, assim como as demais funções desempenhadas em exercício do Poder, têm enfrentado diversos desafios para melhorar a prestação de seus serviços. Não obstante, no caso do Judiciário, o Conselho Nacional de Justiça (CNJ) foi criado para cuidar da programação de políticas públicas voltadas para o sistema judicial, a fim de gerar eficiência nas atividades de administração da Justiça em várias frentes, dentre as quais, o estabelecimento das suas metas e a implantação da informatização. Em que pese no Brasil a Reforma do Judiciário só ter vindo em 2004, já havia sido muito debatida na década de 1990.

Para Andrade e Rossetti (2010, p. 558) “Boas e rígidas regras de governança podem ser estabelecidas tanto para coibir o uso de mecanismos de anulação das forças de controle do Estado quanto para limitar os fatores que favorecem o oportunismo e a expropriação". Então, qual a relação entre governança judiciária e a informatização?

Mesmo que a priori possa-se responder que a informatização e suas características geram mudanças físicas e de gestão para comportar as novas tecnologias, deve-se recordar, conforme observa Gonçalves (2013, p. 69), que

Os Tribunais constituem uma organização, no sentido de que são sistemas voltados
para decisão. Enquanto tal, apresentam as características das organizações: pessoal,
carreira e hierarquia. É uma organização a um só tempo política e jurídica, o que
significa que na sua atividade podem ser observados os acoplamentos de direito e
política, ou seja, também suas diferenças.

Por isso, os serventuários da Justiça devem apresentar uma formação e capacitação específica de modo a adaptar-se aos novos tempos. O que é virtual, busca a todo tempo eliminar qualquer movimentação física e, consequentemente, a redução do serviço burocrático com maior celeridade no trâmite processual. 
Como ensina Santos (2005, p. 105), "No que respeita ao impacto das novas tecnologias de comunicação e de informação na administração da justiça, abrem-se imensas oportunidades para melhorar a eficácia e racionalizar a gestão dos tribunais". Na mesma perspectiva Calhao (2010, p. 229)

Em síntese, é a conjugação das obrigações de meio e resultado como mandamento da boa administração, em sintonia com as matrizes constitucionais aos seus valores, em respeito ao cidadão contribuinte. [...] A sua formatação, a par das diversas técnicas gerenciais a serem adotadas, implicará, contudo, densificar a eficiência com standards administrativos de desempenho, à semelhança dos empregados para aferição do tempo do procedimento judicial, a permitir uma avaliação do sistema judicial no que toca às ações "de meio" e "de resultado".

A governança judiciária, assim, claramente estabelece vantajosa relação de mutualismo com a informatização, mas, para que se possa operacionalizar esta relação, fornecendo mecanismos de gestão administrativa eficientes, eficazes e efetivos, são necessárias mudanças, como antes acima mencionado e ora enfatizado por Bertoncini e Corrêa (2013, p.129)

Tão importante quanto se trabalhar no aperfeiçoamento e unificação dos sistemas, é fundamental que se estruturem os fóruns e se ofereça treinamento aos servidores do Poder Judiciário para que estejam aptos a compreender e operar com os novos sistemas, próprios do processo eletrônico. É preciso que haja boa vontade dos operadores do Direito e dos tribunais no entendimento de que o processo eletrônico ainda não é obra acabada, e justamente por essa razão merece uma implementação gradual e serena, afinal, o processo virtual será construído por todos nós, tudo indicando ser ele o substituto do processo físico dos nossos dias.

Pressupõe ainda, tal espécie de governança, um diálogo com a sociedade e especialmente entre os atores do Judiciário, como os magistrados, advogados, membros do Ministério Público e, principalmente, os próprios serventuários da Justiça.

A aplicação da governança judiciária, de conseguinte, consubstancia-se em um desafio imprescindível que deve ser superado para que se alcance o sucesso das metas traçadas pelo Conselho Nacional de Justiça. Por isso, calha trazer-se à colação as lições de Andrade e Rossetti (2010, p. 562) que, ao diferenciarem governabilidade de governança com seus respectivos princípios $^{8}$, sintetizam bem a ideia aqui exposta

\footnotetext{
${ }^{8}$ Em uma classificação e conceituação sintéticas dos princípios norteadores de governança corporativa, os quais inspiram também a governança pública, tem-se: disclosure - transparência; fairness - tratamento correto a ser dispensado aos acionistas minoritários, implicando um senso de justiça das medidas tomadas; accountability sistema de informações precisas e oportunas que possibilitem a prestação de contas ao público dos atos de gestão; compliance - o cumprimento das leis, normas, regulamentos e determinações, significando, ainda, aquiescência e conformidade a implicar uma legitimidade dos atos praticados. A esta lista, acrescenta-se proporcionalidade - intervenção quando necessário, com as decisões sendo adequadas aos riscos estabelecidos, identificando-se e minimizando-se os custos envolvidos -, consistência, também chamada de coerência racionalidade das medidas tomadas -, e foco, dito igualmente focalização, orientação ou segmentação regulação centrada em torno do problema e da minimização dos seus efeitos colaterais. Para aprofundar estudos recomenda-se Carvalho (2002).
} 


\begin{abstract}
As instituições políticas e as revelações impunes de corrupção são consistentes com estas avaliações. E mostram que a questão-chave do Estado não é a governabilidade, mas de governança. Enquanto a primeira é uma conquista circunstancial e geralmente efêmera do poder estabelecido, a segunda é uma conquista da sociedade, estrutural e duradoura. E que estará necessariamente alicerçada nos quatro princípios que definem a boa governança das corporações: fairness, disclosure, accountability e compliance.
\end{abstract}

Da mesma maneira, a Direção Nacional de Contratações Públicas do Paraguai, por intermédio do seu Código de Bom Governo (2015, p. 04), também diferencia governabilidade de governança

Governabilidade: Conjunto de condições que façam factível a um governante ou diretor em exercício real do poder que formalmente lhe tenha sido entregue para o cumprimento dos objetivos e fins sob a responsabilidade de seu cargo. Esta capacidade de conduzir o coletivo se origina no grau de legitimidade que os diversos grupos de interesse concedem à direção, e se joga no reconhecimento de: a) Sua competência e idoneidade para administrar a Instituição na obtenção dos objetivos estratégicos -eficiência e eficácia-; b) O cumprimento de princípios e valores éticos e a priorização do interesse geral sobre o particular -integridade-; e c) La comunicação para tornar visíveis a forma como se administra e os resultados obtidos -transparência-. Governança Corporativa: Maneira em que as Instituições são dirigidas, melhorando seu funcionamento interno e externo, buscando eficiência, transparência e integridade, para responder adequadamente ante seus grupos de interesse, assegurando um comportamento ético-organizacional ${ }^{9}$.

Para tanto, um organograma auxilia para dar uma visão sistêmica às pessoas da organização e deve ser apresentado como um arquétipo em que se tenha a inclusão das unidades administrativas, varas, câmaras, Tribunal com a presidência e demais setores, pois, como ensina Sadek (2004, p. 03), modelos são essenciais

Da mesma forma, o modelo institucional estabelece parâmetros que produzem efeitos concretos. O maior ou menor grau de participação do Judiciário e de seus integrantes na vida pública está fortemente condicionado pelos imperativos constitucionais e pelo modelo institucional.

Talvez um dia, com o estabelecimento de uma cultura de gestão, ter-se-á o ideal em que, os juízes serão também administradores ou especialistas em governança, julgando e gerindo com a mesma eficácia e eficiência. Como aduz Sadek (2004, p. 22)

Porém, a forma de recrutamento, por concursos, e a mentalidade formada por faculdades de Direito tradicionais tendem a manter o corporativismo interna corporis, afastando inovações externas. De outra sorte, a exigência da qualificação do juiz-gestor, para atuar conjuntamente com o diretor, na organização e no controle

\footnotetext{
${ }^{9}$ No original: Gobernabilidad: Conjunto de condiciones que hacen factible a un gobernante o director el ejercicio real del poder que formalmente se le ha entregado para el cumplimiento de los objetivos y fines bajo la responsabilidad de su cargo. Esta capacidad de conducir al colectivo se origina en el grado de legitimación que los diversos grupos de interés conceden a la dirigencia, y se juega en el reconocimiento de: a) Su competencia e idoneidad para administrar la Institución en el logro de los objetivos estratégicos -eficiencia y eficacia-; b) El cumplimiento de principios y valores éticos y la priorización del interés general sobre el particular -integridad-; y c) La comunicación para hacer visibles la forma como se administra y los resultados obtenidos -transparencia-. Gobierno Corporativo: Manera en que las Instituciones son dirigidas, mejorando su funcionamiento interna y externamente, buscando eficiencia, transparencia e integridad, para responder adecuadamente ante sus grupos de interés, asegurando un comportamiento ético organizacional.
} 
dos serventuários, requer aperfeiçoamento - que deve se iniciar em faculdades de Direito e ter continuidade através de escolas preparatórias e cursos de aperfeiçoamento.

\section{BOAS PRÁTICAS DE GESTÃO ADMINISTRATIVA E A TECNOLOGIA}

Quando se pensa em enfrentamento dos paradigmas da eficiência, eficácia e efetividade no Poder Judiciário, deve-se ter em mente que os desafios da Justiça, além de permitirem maior acesso às pessoas (o que resulta, indubitavelmente, num constante aumento da quantidade de processos), implicam um olhar para dentro dos seus quadros, criando-se a cultura de diálogo institucional e gerencial. Conforme salientado por Calhao (2010, p. 274)

Em sentido estrito, a doutrina administrativa cunhou o conceito de cidadania administrativa, que projetada para o âmbito dos sistemas judiciais traduz-se na reorganização de suas estruturas, visando à concretização de direitos enquanto aspiração maior do sentido reformista. Dialogando com esta premissa, é de se reconhecer a presteza jurisdicional como um atributo da boa governança, não tanto como uma reiteração das dimensões materiais do direito à jurisdição célere, mas na linha adotada por Canotilho, como a explicitação das suas dimensões materiais e processuais a que o Estado se obriga cumprir e tutelar.

No mesmo sentido, Santos (1986, p. 32) afirma

A contribuição maior da sociologia para a democratização da administração da justiça consiste em mostrar empiricamente que as reformas do processo ou mesmo do direito substantivo não terão muito significado se não forem complementadas com outros dois tipos de reformas. Por um lado, a reforma da organização judiciária, a qual não pode contribuir para a democratização da justiça se ela própria não for internamente democrática. E neste caso a democratização deve correr em paralelo com a racionalização da divisão do trabalho e com uma nova gestão dos recursos de tempo e de capacidade técnica.

Diante disso, aliando o pensamento da boa governança com a informatização, desde a publicação da Lei $n^{\circ}$ 11.419/2006 que instituiu o processo judicial eletrônico, a Justiça ampliou, e muito, sua experiência no uso dos meios eletrônicos para aperfeiçoar sua gestão.

Assim, aproveitando a estrutura instalada para o processo judicial eletrônico, questiona-se sobre a possibilidade de criação de mecanismos eletrônicos ou informáticos para ajudar na governança e na gestão administrativa de modo geral. E em resposta a tal questionamento é que o CNJ criou a Rede de Governança Colaborativa do Poder Judiciário (art. 11, caput e $\S \S 1^{\circ}$ a $3^{\circ}$, da Resolução n ${ }^{\circ} 198$, de 1 de julho de $2014^{10}$ ).

Nos Encontros Nacionais do Poder Judiciário é onde se faz a avaliação da estratégia nacional de governança, bem como a divulgação e premiação não apenas do cumprimento das Metas Nacionais (por si aprovadas, para o biênio subsequente, ou ajustadas, quanto às do

\footnotetext{
${ }^{10}$ Dispõe sobre o planejamento e a gestão estratégica no âmbito do Poder Judiciário e dá outras providências. Disponível em: http://www.cnj.jus.br/busca-atos-adm?documento=2733. Acesso em 23 de jun. de 2016.
} 
encontro anterior, juntamente com as diretrizes e iniciativas estratégicas ${ }^{11}$ ), como também da criação e implantação de boas práticas de gestão.

Em paralelo, criou-se também o Banco de Boas Práticas e Ideias para o Judiciário (BPIJus) (art. 13, da Resolução $\mathrm{n}^{\circ}$ 198, de 1 de julho de 2014), continuamente atualizado para incentivar a disseminação e o compartilhamento de boas práticas e ideias inovadoras de governança. Sua criação, vale ressaltar, caracterizou-se como uma iniciativa bastante positiva, a qual inspirou outros Tribunais pelo país a terem seus próprios bancos de boas práticas de administração pública, de âmbitos locais e regionais. São várias as iniciativas, muitas delas, inclusive, contempladas pelo Prêmio Innovare ${ }^{12}$, despertando nos juristas uma perspectiva de administrador que diretamente auxilia na eficiência, eficácia, efetividade e sustentabilidade das atividades não apenas de prestação jurisdicional, mas também judiciárias.

Diante da autorização normativa do órgão gestor, muitos Tribunais pelo Brasil iniciaram o uso de ferramentas de gestão desenvolvidas pelos próprios órgãos que orientam de alguma maneira a gestão administrativa (art. 12, § $2^{\circ}$, da Resolução CNJ no 211, de 15 de dezembro de 2015).

Como exemplo, pode-se citar o Sistema de Gestão de Recursos Humanos - SGRH, implantado pelo Tribunal Regional do Trabalho da $2^{\mathrm{a}}$ Região ${ }^{13}$, que possui uma ferramenta que centraliza todas as informações funcionais do quadro de magistrados e servidores e que padronizam procedimentos, permitindo assim, que a área dedicada aos Recursos Humanos elimine parte das tarefas operacionais e se concentre em atividades intelectuais, como a gestão por competências. Outra boa prática de gestão, oriunda do TRT $2^{\mathrm{a}}$ Região ${ }^{14} \mathrm{em}$ parceria com o Tribunal Regional do Trabalho da $12^{\mathrm{a}}$ Região $^{15}$, é o chamado PROAD, sistema que institui o Processo Administrativo Eletrônico.

A seu turno, o Tribunal Regional do Trabalho da $13^{\mathrm{a}}$ Região (PB) inovou com o Sistema eletrônico chamado Hórus, cujos dados judiciais e administrativos são facilmente

\footnotetext{
${ }^{11}$ Conselho Nacional de Justiça - CNJ. Metas 2016. 2015d. Disponível em: http://www.cnj.jus.br/gestao-eplanejamento/metas/metas-2016. Acesso em 21 de jun. 2016.

12 Vide Instituto Innovare. Sobre o Prêmio Innovare. Disponível em: http://www.premioinnovare. com.br/inscricoes. Acesso em 23 de jun. 2016.

${ }^{13}$ Tribunal Regional do Trabalho da $2^{\mathrm{a}}$ Região. Regionais decidem adotar SGRH como ferramenta de gestão. Disponível em: http://www.trtsp.jus.br/indice-noticias-em-destaque/18712-regionais-decidem-adotar-sgrhcomo-ferramenta-de-gestao. Acesso em 23 de jun. 2016.

14 Tribunal Regional do Trabalho da $2^{\text {a }}$ Região. ATO GP no 19/2016, de 13 de junho de 2016. Institui o Processo Administrativo Eletrônico - PROAD no âmbito do Tribunal Regional do Trabalho da $2^{\text {a }}$ Região e dá outras providências. Disponível em: http://www.trtsp.jus.br/geral/tribunal2/Normas_Presid/Atos/2016/GP_19 _16.html. Acesso em 23 de jun. 2016.

${ }^{15}$ Tribunal Regional do Trabalho da $12^{\mathrm{a}}$ Região. Muito mais que um sistema. Disponível em: http://www.trt12.jus.br/portal/areas/ascom/extranet/ materias\%20relacionadas/Proad_muito_mais_do_que_um_sistema.jsp. Acesso em 24 de jun. de 2016.
} 
coletados de um sistema gestor informatizado, o e-Gestão, e formatados estatisticamente, facilitando o acompanhamento da execução de planejamento e obtenção de $\operatorname{metas}^{16}$.

Há, ainda, outros Tribunais e várias outras boas práticas sendo implantadas, dentre as quais cabe evidenciar a decorrente justamente da junção das técnicas contemporâneas de gestão administrativa com os mais recentes recursos tecnológicos e de informatização, e que possibilita o chamado home office $e^{17}$.

Esses são apenas alguns exemplos que certamente podem fazer parte de um futuro grande banco de boas práticas de governança pública e, assim como outros, ser implantados em todo o Judiciário, padronizando e otimizando procedimentos para que a eficiência das atividades judiciárias e judiciais seja de fato empregada em toda a cadeia processual, agregando, ainda, eficácia, efetividade e sustentabilidade dentro da concepção do Triple Bottom Line.

E, a prol das inovações participativas, decorrentes de ideias e boas práticas de gestão pública que se unam ao componente tecnológico e de informatização, Santos (2005, p. 107) afirma que

É urgente, pois, explorar as potencialidades democráticas das novas tecnologias, as novas possibilidades de democracia deliberativa e participativa, as novas formas de controle público, tanto do Estado como da produção privada de bens públicos. A relação virtuosa entre tribunais, comunicação social e novas tecnologias de informação e de comunicação depende menos daquilo que os três vectores deste triângulo acordarem entre si do que do controle público que sobre que cada um deles exercerem os cidadãos activos, dotados de competências para exercícios de democracia de alta intensidade.

\section{CONCLUSÕES}

Postos tais esforços acima constatados, se por um lado não se pode mais acusar o Judiciário de ser o arauto da morosidade processual, é preciso, de outro lado, intensificaremse as iniciativas para um contínuo aprimoramento e adaptação da legislação e demais normatizações em vigor, além de se buscar a superação do componente cultural, arraigado à tradição das antigas práticas, com a educação e capacitação das pessoas para resolução de conflitos por meios eletrônicos, de sorte a facilitar-lhes o acesso ao Judiciário, inclusive.

\footnotetext{
${ }^{16}$ Tribunal Regional do Trabalho da $13^{a}$ Região. Banco de Boas Práticas. Sistema Hórus. Disponível em: https://www.trt13.jus.br/age/banco-de-boas-praticas/sistema-horus. Acesso em 23 de jun. de 2016.

${ }_{17}$ Conselho Nacional de Justiça - CNJ. Aprovada resolução que regulamenta o teletrabalho no Poder Judiciário. 2015f. Disponível em: http://www.cnj.jus.br/noticias/cnj/ 82591-aprovada-resolucao-queregulamenta-o-teletrabalho-no-poder-judiciario_blank. Acesso em 21 de jun. 2016). Vide Resolução no227, de junho de 2015. 2015c. Regulamenta o teletrabalho no Poder Judiciário e dá outras providências. 2015c. Disponível em: http://www.cnj.jus.br/atos_normativos/resolucao/resolucao_227_15062016_17062016161058. pdf. Acesso em 21 de jun. 2016.
} 
O estabelecimento de um planejamento estratégico em uma instituição, seja ela pública ou privada, deve privilegiar um modelo de governança que permita fazer desta cultura de gestão administrativa uma política efetiva de Estado, de forma permanente e não de mera gestão temporária. Nesta perspectiva, no caso do Poder Judiciário, o papel do gestor, seja ele o juiz titular de determinada vara, ou um diretor de secretária, deverá adequar-se à estratégia de execução dos processos e dos indicadores de desempenho com uso das novas tecnologias.

A evolução tecnológica incentiva maior diálogo e consequente democratização dos processos que, por sua vez, facilitam o controle social e a participação popular nas políticas públicas. Vale ressaltar que as principais mudanças trazidas para a organização administrativa do Poder Judiciário, diante da introdução do processo judicial eletrônico e das boas práticas de gestão com o uso de ferramentas tecnológicas (informatização de rotinas), para além de uma questão meramente conceitual de governança, implicam sustentabilidade ao economizarem recursos e tempo, entre outros benefícios.

A gestão administrativa do Poder Judiciário pode ser facilitada com a ideia de se construir uma experiência de governança que permita aos Tribunais brasileiros utilizarem-se das novas tecnologias divulgando, adaptando e implementando as boas práticas de gestão que direta ou indiretamente dão maior eficiência e efetividade à prestação jurisdicional.

Eficiência e celeridade na prestação jurisdicional passam pela acepção de governança e boas práticas de gestão, a implicar democratização do processo e modernização dos sistemas judiciais e judiciários.

\section{REFERÊNCIAS}

ADORNO JÚNIOR, Hélcio Luiz; SOARES, Marcele Carine dos Praseres. Processo judicial eletrônico, acesso à justiça e inclusão digital: os desafios do uso da tecnologia na prestação jurisdicional. Universitas. Ano 6, no 11 - jul./dez. 2013, p. 65-85. Disponível em: http://revistauniversitas.inf.br/index.php/UNIVERSITAS/article/view/113/94. Acesso em 20 de jun. de 2016.

ANDRADE, Adriana; ROSSETTI, José Paschoal. Governança Corporativa: fundamentos, desenvolvimento e tendências. $4^{\mathrm{a}}$ ed. atualizada e ampliada. São Paulo: Atlas, 2010. 
ATHENIENSE, Alexandre. As vulnerabilidades e soluções para o processo eletrônico. Revista do Advogado. São Paulo: AASP, ano 33, nº 120, ago. 2013, p. 9-19.

BECK, Ulrich. O que é Globalização? Equívocos do globalismo: respostas à globalização. CARONE, André (Trad.). São Paulo: Paz e Terra, 1999.

BERTONCINI, Mateus Eduardo Siqueira Nunes; CORRÊA, Felippe Abu-Jamra. Processo eletrônico como instrumento da cidadania. In: SILVEIRA, Vladmir Oliveira da; MEZZAROBA, Orides; COUTO, Mônica Bonetti Couto; NASPOLINI SANCHES, Samyra Haydee Dal Farra (Coord.). Justiça e [o Paradigma da] Eficiência: celeridade processual e efetividade dos direitos. Coleção: Justiça, Empresa e Sustentabilidade [vol. 3]. Curitiba: Editora Clássica, 2013, p. 115-132.

BRASIL. Governo Eletrônico. Disponível em: http://www.governoeletronico.gov.br/. Acesso em 19 de jun. 2016.

Lei $\mathrm{n}^{\circ}$ 11.419, de 19 de dezembro de 2006. Dispõe sobre a informatização do processo judicial e dá outras providências. Diário Oficial da República Federativa do Brasil. Brasília, DF, 19 dez. 2006.

BRESSER PEREIRA, Luiz Carlos. Reforma do Estado para a Cidadania. $1^{\text {a }}$ ed. São Paulo: Editora 34; Brasília: ENAP, 1998.

CALHAO, Antônio Ernani Pedroso. Justiça célere e eficiente: uma questão de governança judicial. São Paulo: LTr, 2010.

CARVALHO, Antonio Gledson de. Governança Corporativa no Brasil em Perspectiva. Revista de Administração. São Paulo: USP, v. 37, n. 3, jul./set. 2002, p. 19-32.

CHAVES, Luciano Athayde. O juiz e a governança do poder judiciário: do modelo burocrático ao democrático. Revista da EJUSE. Aracaju: EJUSE/TJ, n 20, 2014. p. 25-54. Disponível em: http://www.diario.tjse.jus.br/revistaesmese/revistas/20.pdf. Acesso em 22 de jun. de 2016. 
Conselho Nacional de Justiça - CNJ. Resolução no 182 de 17 de outubro de 2013. Dispõe sobre diretrizes para as contratações de solução de tecnologia da informação e comunicação pelos órgãos submetidos ao controle administrativo e financeiro do Conselho Nacional de Justiça (CNJ). Disponível em: http://www.cnj.jus.br/atosnormativos?documento=1874. Acesso em 20 de jun. de 2016.

Resolução $\mathbf{n}^{0}$ 198, de 1 de julho de 2014. 2014b. Dispõe sobre o planejamento e a gestão estratégica no âmbito do Poder Judiciário e dá outras providências. Disponível em: http://www.cnj.jus.br/busca-atos-adm?documento=2733. Acesso em 23 de jun. de 2016.

- Relatório Justiça em Números - 2015: ano-base 2014. 2015a. Disponível em: http://www.cnj.jus.br/programas-e-acoes/pj-justica-em-numeros. Acesso em 18 jun. de 2016.

Resolução no 211, de 15 de dezembro de 2015. 2015b. Institui a Estratégia Nacional de Tecnologia da Informação e Comunicação do Poder Judiciário (ENTIC-JUD). Disponível em: http://www.cnj.jus.br/atos-normativos?documento=2227. Acesso em 22 de jun. 2016.

Resolução no 227, de junho de 2015. 2015c. Regulamenta o teletrabalho no Poder Judiciário e dá outras providências. 2015c. Disponível em: http://www.cnj.jus.br/atos_normativos/resolucao/resolucao_227_15062016_1706201616105 8. pdf. Acesso em 21 de jun. 2016.

Metas 2016. 2015d. Disponível em: http://www.cnj.jus.br/gestao-eplanejamento/metas/metas-2016. Acesso em 21 de jun. 2016.

\section{Aprovada resolução que regulamenta o teletrabalho no Poder}

Judiciário. 2015e. Disponível em: http://www.cnj.jus.br/noticias/cnj/82591-aprovadaresolucao-que-regulamenta-o-teletrabalho-no-poder-judiciario_blank. Acesso em 21 de jun. 2016. 
ELKINGTON, John. Enter the Triple Bottom Line. In: HENRIQUES, Adrian; RICHARDSOn, Julie. The Triple Bottom Line, Does It All Add Up?: Assessing the Sustainability of Business and CSR. London; Earthscan Publications Ltd. 2004, cap. 1, p. 116. Disponível em: http://kmhassociates.ca/resources/1/Triple\%20Bottom\%20Line \%20a\%20history\%201961-2001.pdf. Acesso em 20 de jun. 2016.

FERNANDES, Jorge Ulisses Jacoby. Tribunais de contas do Brasil: jurisdição e competência. Belo Horizonte : Fórum, $1^{\mathrm{a}}$ ed., $2^{\mathrm{a}}$ tiragem, 2003.

FERRAZ JÚNIOR, Tércio Sampaio. Teoria da norma jurídica: ensaio de pragmática da comunicação normativa. $4^{\mathrm{a}}$ ed. Rio de Janeiro: Editora Forense, 2006.

GONÇALVES, Maciel Gláucio. A organização dos tribunais e a gestão do tempo. In: SILVEIRA, Vladmir Oliveira da; MEZZAROBA, Orides; COUTO, Mônica Bonetti Couto; NASPOLINI SANCHES, Samyra Haydee Dal Farra (Coord.). Justiça e [o paradigma da] eficiência: celeridade processual e efetividade dos direitos. Coleção: Justiça, Empresa e Sustentabilidade [vol. 3]. Curitiba: Editora Clássica, 2013, pp. 65-83.

Instituto Innovare. Sobre o Prêmio Innovare. Disponível em: http://www.premioinnovare. com.br/inscricoes. Acesso em 23 de jun. 2016.

JORGE NETO, Francisco Ferreira; CAVALCANTE, Jouberto de Quadros Pessoa; MENESES, Judson Sales de. Reflexões e cautelas na implementação do processo judicial eletrônico. Revista Justiça do Trabalho. Porto Alegre : HS Editora, n.358, out. 2013, p.3552.

MATA DIZ, Jamile B.; CALDAS, Roberto C. da S. G. Aspectos estruturais e funcionais do controle orçamentário e da gestão eficiente: análise dos Tribunais de Contas do Brasil e da União Europeia. Revista do Tribunal de Contas do Estado de Minas Gerais. Belo Horizonte, v. 33, n. 3, jul./set. 2015, p. 56-72.

MOREIRA NETO, Diogo de Figueiredo. Políticas públicas e parcerias: juridicidade, flexibilidade negocial e tipicidade na administração negocial. BLC - Boletim de licitação e 
contratos. São Paulo : NDJ - Nova Dimensão Jurídica, ano 21, nº 1, janeiro de 2008, p. 3442.

O paradigma do resultado. In: Grandes temas do Direito Administrativo: homenagem ao Professor Paulo Henrique Blasi. CARLIN, Volnei Ivo. (Org.). Florianópolis: Millenium, 2009, p. 215-228.

PARAGUAI. DNCP - Dirección Nacional de Contrataciones Públicas. Código de Buen Gobierno 2015. 2015. Disponível em file:///C:/Users/rober_000/Documents/CODIGO _DE_BUEN_GOBIERNO_2015Paraguai.pdf. Acesso em 20 de jun. de 2016.

PINHO, José Antonio Gomes de; SACRAMENTO, Ana Rita Silva. Accountability: já podemos traduzi-la para o português? Revista de Administração Pública. Rio de Janeiro 43(6): $\quad$ nov./dez. $\quad 2009, \quad$ p. $1.343-1.368 . \quad$ Disponível $\quad$ em http://www.scielo.br/pdf/rap/v43n6/06.pdf. Acesso em 20 de jun. de 2016.

PRAZERES, Paulo Mundin. Minidicionário de termos da qualidade. São Paulo : Atlas, 1997.

SADEK, Maria Tereza A. Poder Judiciário: Perspectivas de Reforma. Opinião Pública. Campinas, v. 10, n. 1, maio 2004, p. 1-62.

SANTOS, Boaventura de Sousa. Introdução à sociologia da administração da justiça. Revista Crítica de Ciências Sociais, $\mathrm{n}^{\circ}$ 21, nov. de 1986, p. 11-37. Disponível em file://C:/Users/rober_000/Downloads/Introdu\%C3\%A7\%C3\%A30\%20\%C3\%A0\%20Sociolo gia\%20da\%20Administra\%C3\%A7\%C3\%A3o\%20da\%20Justi\%C3\%A7a.pdf. Acesso em 20 de jun. de 2016.

Os tribunais e as novas tecnologias de comunicação e de informação. Sociologias. Porto Alegre, ano 7, n⿳0 13, jan./jun. 2005, p. 82-109.

Tribunal Regional do Trabalho da $2^{\text {a }}$ Região. Regionais decidem adotar SGRH como ferramenta de gestão. Disponível em: http://www.trtsp.jus.br/indice-noticias-em- 
destaque/18712-regionais-decidem-adotar-sgrh-como-ferramenta-de-gestao. Acesso em 23 de jun. 2016.

Tribunal Regional do Trabalho da $2^{\text {a }}$ Região. ATO GP no 19/2016, de 13 de junho de 2016. Institui o Processo Administrativo Eletrônico - PROAD no âmbito do Tribunal Regional do Trabalho da $2^{\text {a }}$ Região e dá outras providências. Disponível em: http://www.trtsp.jus.br/geral/tribunal2/Normas_Presid/Atos/2016/GP_19_16.html. Acesso em 23 de jun. 2016.

Tribunal Regional do Trabalho da $12^{\mathrm{a}}$ Região. Muito mais que um sistema. Disponível em: http://www.trt12.jus.br/portal/areas/ascom/extranet/materias\%20relacionadas/Proad_muito_ mais_do_que_um_sistema.jsp. Acesso em 24 de jun. de 2016.

Tribunal Regional do Trabalho da $13^{a}$ Região. Banco de Boas Práticas. Sistema Hórus. Disponível em: https://www.trt13.jus.br/age/banco-de-boas-praticas/sistema-horus. Acesso em 23 de jun. de 2016.

ZAFFARONI, Eugenio Raúl. Poder Judiciário: crise, acertos e desacertos. TAVARES, Juarez (Trad.). São Paulo: Revista dos Tribunais, 1995. 